11 a 13 de setembro de 2019 - Universidade de Brasília UnB

\title{
SISTEMA DE DESENVOLVIMENTO DE PRODUTO DO MODELO FAST FASHION: UM ESTUDO DE CASO NA INDÚSTRIA DE CONFECÇÃO DE CAMISAS MASCULINAS
}

Flávia Nunes Ferreira (flavianfe@gmail.com) - Escola de Engenharia / Universidade Federal de Minas Gerais

Eduardo Romeiro Filho (edu.romeiro@gmail.com) - Universidade Federal de Minas Gerais

\section{RESUMO}

A indústria do vestuário tem passado por diferentes cenários nas últimas décadas e, junto às revoluções tecnológicas e o advento da internet, a moda tornou-se mais efêmera, surgindo um novo modelo de negócios de varejo denominado fast fashion. Este é um conjunto de estratégias de produção rápida de produtos que contemplam as tendências eminentes de moda, adotado por crescente o número de empresas no Brasil, onde é quase inexistente a adoção de metodologias ou modelos formalizados de desenvolvimento de produto. Além disso, a aplicação da moda rápida pela indústria nacional foi pouco estudada e a organização do seu sistema criativo e de desenvolvimento de produto ainda pouco difundida. Tendo em vista esta situação, este artigo tem como objetivo a avaliação do modelo de negócios de moda fast fashion nas indústrias brasileiras, elaborado através da abordagem bibliográfica sobre o modelo e métodos de desenvolvimento de produtos de moda, além de um estudo de caso em uma indústria de camisas masculinas de médio porte.

Palavras-chave: Sistema de Desenvolvimento de Produto, Fast Fashion, Indústria de Confecção. 


\section{INTRODUÇÃO}

Pode-se dizer que praticamente todos os modelos mercadológicos existentes são de alguma forma, direta ou indiretamente, baseados no consumo, pois é fomento para tomada de decisões das empresas no mercado, seja no setor têxtil ou em qualquer outro. Assim, moda e consumo se tornam faces da mesma moeda. Um novo fenômeno mercadológico da moda aparece em resposta a este atual momento do consumo, a moda rápida ou fast fashion. A moda rápida nasce para atender os anseios do consumidor e acompanha os desejos de consumo com a velocidade com que as tendências aparecem, com produtos híbridos. Neste sentido, é possível afirmar que, a criação do produto de moda é contínua e quem dita às novas demandas é o consumidor.

O lançamento de produtos diferenciados rapidamente tem sido apontado como saída para a crescente pressão competitiva. Portanto, processos de desenvolvimento de produto organizados, no que diz respeito ao sequenciamento das atividades e a integração entre os departamentos, não são triviais para a elaboração de produtos de sucesso, reduzindo o tempo entre o planejamento do produto e o seu lançamento. Sabe-se pouco sobre as experiências dos empreendimentos brasileiros que adotam o modelo fast fashion devido à falta de estudos realizado (CIETTA, 2010). Porém, um dado relevante da indústria da moda nacional afirma que inúmeras delas possuem sistemas de desenvolvimento de produto, mas de baixo nível de organização (OLIVEIRA, 2007). Com isso surge a questão: como as pequenas e médias empresas que adotam o modelo fast fashion desenvolvem seus produtos?

Neste contexto, fazem-se necessários estudos sobre organização e estruturação do processo de desenvolvimento de produtos das indústrias do vestuário. O presente estudo pretende contribuir com informações para a sobrevivência e sucesso deste segmento de produtos de ciclos curtos, que pretende atender consumidores exigentes tanto no design como na inovação. O objetivo é analisar o sistema de desenvolvimento de produto (SDP) aplicada nas indústrias têxteis que utilizam o modelo fast fashion e, com base nos modelos de desenvolvimento de produto encontrados na literatura, levantar dados para melhorias desse processo que permita a elaboração de projetos mais ágeis, robustos e eficazes.

Para realização da proposta, realizou-se revisão de literatura e estudo de caso do sistema de desenvolvimento de produto do modelo fast fashion, em uma pesquisa exploratória, de abordagem qualitativa e de natureza aplicada, a qual há o interesse de aplicação, utilização e 
consequências práticas dos conhecimentos gerados numa realidade circunstancial (GIL, 2019), mediante análises documentais, entrevistas, depoimentos pessoais, observação espontânea e análise de artefatos físicos.

\section{FAST FASHION}

Segundo Cietta (2010), fast fashion nada mais é que um modelo de negócios adotado por determinada marca/empresa. Não é um posicionamento de mercado ou uma tendência de moda, é um modelo de varejo com várias cadeias produtivas complexas, atuando em conjunto, e que, para o pleno funcionamento, devem estar muito bem estruturadas. $\mathrm{O}$ sistema tem chamado atenção do mercado do vestuário por ser capaz de reproduzir de forma singular às tendências e desejos dos consumidores. Perante os valores imateriais inseridos no consumo de moda, o modelo de produção e distribuição rápida ganha força no setor de vestuário. Capaz de responder satisfatoriamente às exigências do consumo acelerado, a moda rápida torna seu sucesso evidente proporcionando as empresas mais venda e consequentemente renda, além da fidelidade dos clientes. Outro aspecto fundamental no sistema em questão é a busca pelo preço acessível. "Produtos de fast fashion são descartáveis e é isso que faz o consumidor voltar à loja e procurar por novidades mais vezes do que procuraria por um produto qualquer" (SANTIAGO; MORELLI, 2010, p. 4). Ainda segundo os autores, os clientes querem se adaptar às tendências de moda, mas não estão dispostos a pagar caro por isso.

O fast fashion, então, é a estratégia em resposta ao hiperconsumo da atualidade. Em busca de agilidade e de minimizar quantidades de estoques, as criações caracterizam-se por serem semiexclusivas - produção em lotes, porém menores e únicos. Valoriza-se a estética e o estilo da roupa, mas de maneira voltada a um mercado popular, em que a exclusividade não o é importante "mas o preço é o fator primordial em detrimento da estética" (DELGADO, 2008, p. 5). O apelo visual prevalece nas coleções e a qualidade deixa de ser prioritária, a fim de atender a demanda pela busca do novo. Essa nova estratégia pode ser considerada um fenômeno mercadológico da moda atual e sem distinção de classes, passa a ser consumida por pessoas de todos os status sociais, predominando a classe média. Atualmente, mesmo que uma marca não adere formalmente a esse modelo, ela é influenciada pelo conceito de moda rápida.

Pode-se dizer, então, que o modelo do fast fashion busca reduzir as incertezas da demanda e, ao mesmo tempo, incrementar o consumo, por meio da produção de produtos de ciclo de vida 
curto, de forma que seu lançamento seja o mais próximo possível do momento da venda e de acordo com os anseios do consumidor naquele momento. Ainda de acordo com Cietta (2010, p.16) o modelo fast fashion "pode, paradoxalmente, ser muito eficaz ao defender o patrimônio produtivo local, desde que consiga explorar a vantagem de saber antecipar as mudanças nas tendências de consumo no mercado local, mais do que os grandes competidores globais". Este modelo pode vir a ser uma estratégia de política empresarial eficaz no desenvolvimento de redes locais, de forma que possa defender a indústria nacional muito melhor que impostos ou barreiras comerciais, visto que a proximidade geográfica e cultural em relação ao mercado é um diferencial significativo neste processo. Além disso, o mercado local oferece importantes indicativos sobre comportamento de consumo para a indústria da moda, como, por exemplo, a "moda de novela" que é uma particularidade do Brasil.

\subsection{DESENVOLVIMENTO DE PRODUTO TÊXTIL}

A partir do processo de desenvolvimento de produto proposto por Slack et al (2018) e Kotler (2011) e o método de projeto de Munari (1998, apud RECH, 2002), RECH (2002) propõe uma metodologia para a indústria têxtil, numa abordagem interdisciplinar e simultânea. Sob essas visões, a autora propõe o desenvolvimento do produto de moda em cinco momentos (figura 1): Geração do Conceito que envolve a análise das coleções anteriores, a definição da direção mercadológica da nova coleção e a avaliação da dimensão da coleção. A Triagem, quando é analisada a elaboração (objeto de inspiração, contemporaneidade da forma e estética), adequação (funcionalidade, aspecto comercial e aspecto cultural) do produto e definição dos temas. O Projeto Preliminar corresponde aos esboços dos modelos e a escolha de cores, formas, tecidos, aviamentos, componentes, acessórios e etiquetas. A Avaliação e Melhoramento, etapa em que desenvolve o desenho técnico, a modelagem e a ficha técnica. Por último o Projeto Final na qual a peça-piloto é desenvolvida e aprovada ou não.

Considerando essa metodologia proposta, percebe-se que, ao estabelecer as ações de projeto, a autora ressalta a importância do planejamento, pela coleta e análises de dados, fundamentais na qualidade do processo. Deste modo, é capaz de identificar as diretrizes para o projeto e processo produtivo, determinado por padrões e requisitos do consumidor. Ao investigar as metodologias de desenvolvimento de produto elaboradas pelos autores anteriormente citados, Montemezzo (2003) apresentou diretrizes para a elaboração de produtos de moda no âmbito acadêmico. Esse método (Figura 2) é destinado ao vestuário, orientado para o mercado com obsolescência 
programada e que contempla, além da função de indumento, valores imateriais e códigos estéticos vigentes.

\begin{tabular}{|c|c|c|}
\hline Ações realizadas & $\begin{array}{c}\text { Desenvolvimento } \\
\text { Produtos/ Moda } \\
\end{array}$ & \\
\hline Análise das coleções anteriores & \multirow{3}{*}{$\begin{array}{l}\text { Geração do } \\
\text { conceito }\end{array}$} & \\
\hline Direcionamento mercadológico & & \\
\hline Dimensão da coleção & & \\
\hline Análise quanto à elaboração & \multirow{3}{*}{ Triagem } & \\
\hline Análise quanto à adequação & & \\
\hline $\begin{array}{l}\text { Informaç̃̃es de moda e } \\
\text { definição do conceito }\end{array}$ & & Ações de projeto \\
\hline Esboços (geração de idéias) & \multirow[b]{2}{*}{$\begin{array}{c}\text { Projeto } \\
\text { preliminar }\end{array}$} & \multirow{2}{*}{$\begin{array}{l}\text { Ferramentas de desenho } \\
\text { Drapping }\end{array}$} \\
\hline Elementos compositivos e materiais & & \\
\hline Desenho técnico & \multirow[b]{2}{*}{$\begin{array}{c}\text { Avaliação } \\
\text { Melhoramento }\end{array}$} & \multirow{5}{*}{$\begin{array}{l}\text { Análise técnica/comercial } \\
\text { (coerência /expectativas } \\
\text { dos consumidores e da } \\
\text { empresa) }\end{array}$} \\
\hline Modelagem e ficha técnica & & \\
\hline Peça-piloto & \multirow{3}{*}{$\begin{array}{l}\text { Prototipagem } \\
\text { Projeto final }\end{array}$} & \\
\hline Embalagem & & \\
\hline Material de divulgação & & \\
\hline
\end{tabular}

FIGURA 1 - Modelo de Desenvolvimento de Produto de Moda proposto por Rech (2002).

A partir das ponderações de Rech (2002) e Montemezzo (2003) sobre o desenvolvimento de produtos de vestuário, pode-se verificar a importância dos aspectos mercadológicos e as necessidades e desejos do consumidor nesse processo. A proximidade com o consumidor é essencial para a elaboração desses produtos, devido ao elevado valor imaterial que a eles são atribuídos. Logo os projetos focados no consumidor é fator fundamental no desenvolvimento e consequentemente o gerenciamento dos riscos terá mais eficiência. O papel das funções de produções imateriais, a flexibilidade e a sazonalidade da produção são características comuns do setor do vestuário, ainda mais acentuadas no segmento fast fashion. Contudo, Cietta (2010) afirma que na moda rápida as atividades criativas desenvolvidas não diferem daquelas adotadas nas indústrias dos modelos tradicionais, porém implica em um sistema criativo capaz de operar de duplo modo: inovador, mas, ao mesmo tempo, que incorpora as últimas tendências de consumo. 


\begin{tabular}{|c|c|}
\hline Etapas & Ações \\
\hline \multirow{5}{*}{ Planejamento } & Percepção do mercado e descoberta de oportunidades \\
\hline & Análises / expectativas e histórico comercial da empresa \\
\hline & Idéias p/produtos/Identificação do problema de design \\
\hline & $\begin{array}{l}\text { Definição de estratégias de marketing, desenvolvimento, } \\
\text { produçâo, distribuição e vendas. }\end{array}$ \\
\hline & Definição do cronograma \\
\hline \multirow{4}{*}{ Especificação do projeto } & Análise e definição do problema de design (diretrizes) \\
\hline & Sintese do Universo do consumidor (fisico e psicológico) \\
\hline & \begin{tabular}{|l|} 
Pesquisa de conteúdo de moda (tendências) \\
\end{tabular} \\
\hline & Delimitação do projeto (objetivas) \\
\hline \multirow{2}{*}{ Delimitação Conceitual } & Geração de conceitos e definição do Conceito Gerador \\
\hline & Definição de princípios funcionais e de estilo \\
\hline \multirow[t]{2}{*}{ Geração de alternativas } & $\begin{array}{l}\text { Geração de alternativas de solução do problema } \\
\text { (esboços/desenhos, estudos de modelos). }\end{array}$ \\
\hline & Definições de configuração, materiais e tecnologias \\
\hline \multirow{5}{*}{ Avaliação e Elaboração } & Seleçaio da(s) melhor (es) alternativa(s) \\
\hline & Detalhamento de configuração (desenho técnico) \\
\hline & $\begin{array}{l}\begin{array}{l}\text { Desenvolvimento de ficha técnica, modelagem e } \\
\text { protótipo }\end{array} \\
\end{array}$ \\
\hline & Testes ergonômicos e de usabilidade \\
\hline & Correçōes/adequações \\
\hline \multirow{9}{*}{ Realização } & Avaliações técnicas e comerciais apuradas \\
\hline & Correções/adequações \\
\hline & graduação da modelagem \\
\hline & $\begin{array}{l}\text { Confecção de Ficha técnica definitiva e Peça piloto } \\
\text { (aprovação técnica e comercial do(s) produto(s)) }\end{array}$ \\
\hline & aquisição de matéria prima e aviamentos \\
\hline & orientação dos setores de produção e vendas \\
\hline & definição de embalagens e material de divulgação \\
\hline & produção \\
\hline & lançamento do(s) produto(s) \\
\hline
\end{tabular}

FIGURA 2 - Diretrizes para a elaboração de produtos de moda proposto por Montemezzo (2003, p. 62).

\section{ESTUDO DE CASO}

O estudo de caso foi fundamentado em entrevistas abertas semi estruturadas com os proprietários e visitas à empresa estudada com o objetivo de avaliar as seguintes variáveis: histórico da empresa, análise sobre o desenvolvimento de produto e processo produtivo e análise da aplicação do fast fashion no processo produtivo e de desenvolvimento de produto da 
empresa, para atender os objetivos desse trabalho, desenvolvido a partir da pesquisa exploratória e fundamentada pela pesquisa bibliográfica.

A empresa atua desde 1987 no mercado de indústria e comércio de roupas, sendo classificada como médio porte, composta internamente por 85 funcionários divididos nas áreas de produção, comercial e administrativa. Localizada em Divinópolis, Minas Gerais, região polo da indústria de confecção no centro oeste de Minas Gerais, denominado polo da moda. Seus principais produtos são camisas masculinas em malha e tecido plano, desenvolvidas para o mercado de lojas multimarcas atacadistas e redes de lojas varejistas, cujo público direcionado é, especialmente, consumidores da classe $\mathrm{C}$ da faixa etária jovem e adulta. São lançados produtos para esse mercado consumidor de acordo com as evidências do momento, por isso a empresa optou por não desenvolver coleções inteiras por estação antecipadamente, adotando lançamento de produtos conforme as predileções sinalizadas pelos consumidores durante cada estação. A comercialização desses produtos é $70 \%$ alcançada por vendas diretas e $30 \%$ por representantes comerciais.

A empresa desenvolve marca própria e confecção para outras marcas (sistema de private label), atendendo outros nichos de mercado, de empresas que compram produtos e os revendem como se fossem de sua produção, com a etiqueta da respectiva marca. Contudo, a produção de marcas próprias representa $60 \%$ do total. No sistema private label, recebe-se das empresas contratantes desenho/fotos das peças a serem feitas, com a escolha prévia dos tecidos e dos diversos aviamentos necessários para a produção da peça piloto e as descrições necessárias, relatado em uma ficha técnica com detalhamento do proposto. Entretanto, é comum a empresa sugerir às contratantes produtos por ela desenvolvidos. Como a empresa atua em diferentes regiões do Brasil, é requisito que ela ofereça produtos que atendam às necessidades diversificadas desses consumidores, apesar de certa homogeneidade do nicho que empresa atua. As ideias de novos produtos surgem principalmente das tendências visualizadas em eventos de moda, nas ruas e em telenovelas. A pesquisa de tendências realizada pela empresa não é conceitual, ou seja, não tem o intuito de detectar comportamentos, ideias ou estilos em ascensão, mas focada em produtos, modelos, peças e estampas já desenvolvidas por marcas conceituadas no segmento de camisas masculinas. Tal postura foi definida na tentativa de diminuir os riscos e a imprevisibilidade inerente aos produtos da moda, assim sendo produz sustentado naquilo que é cotado como sucesso de vendas e está em evidência no mercado. 
A empresa não possui departamento de desenvolvimento de produto formalizado, sendo responsáveis por essas atividades os próprios empresários, que não possuem formação em moda, mas atuam no seguimento desde 1995. A empresa por vezes já contratou estilistas do mercado para desenvolver produtos para a marca própria, mas não há vínculo com a empresa por questões de custo. Lançamento de produtos são realizados semanalmente tanto para marca própria quanto para as demais (private label). Apesar de não possuir procedimento formal que defina a metodologia de desenvolvimento de produtos, durante as visitas e entrevistas com os empresários observou-se e pôde-se determinar que nesse processo usualmente adotam-se as seguintes fases (Figura 3): 


\section{Sequência de etapas para o desenvolvimento de produtos}

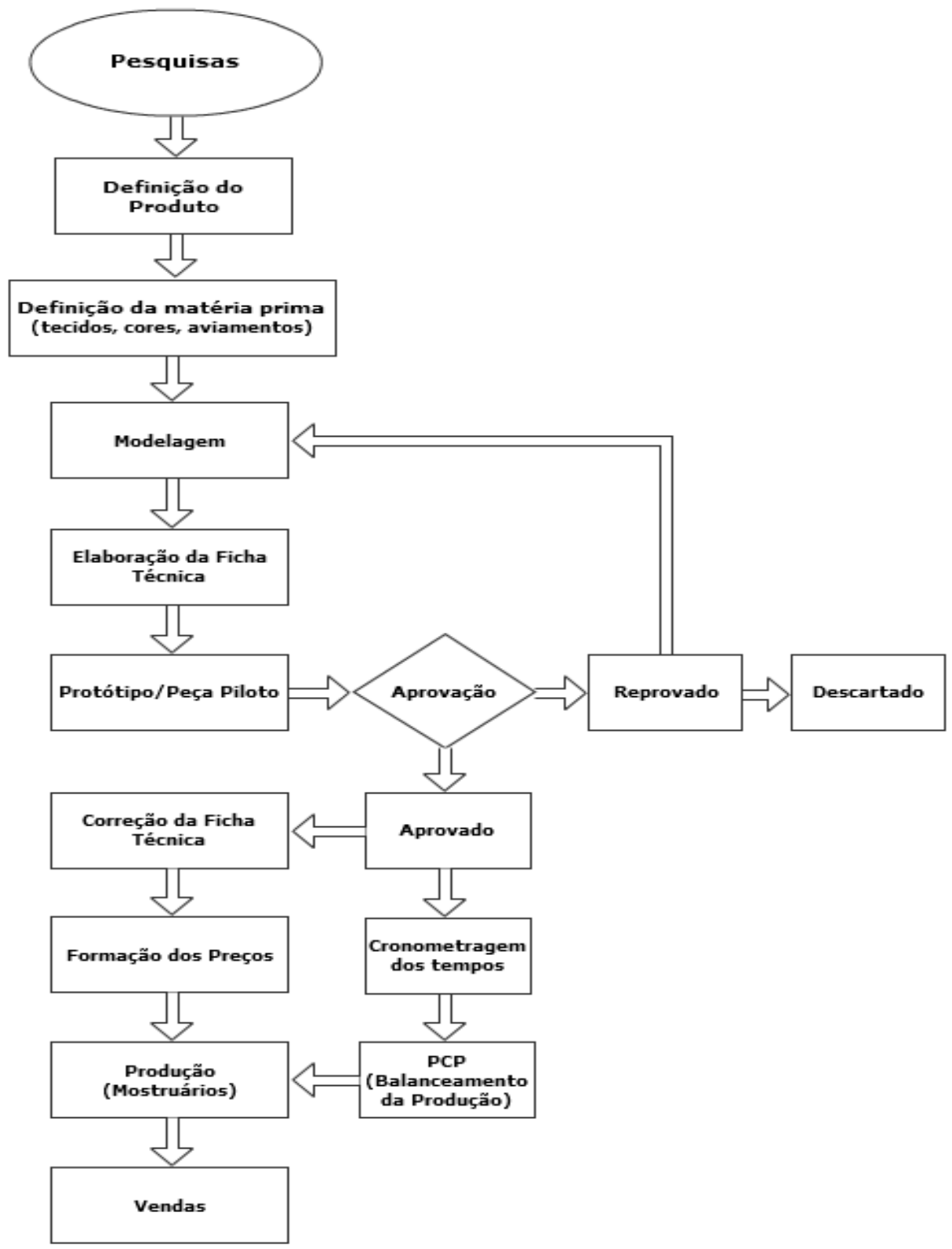

FIGURA 3 - Fluxograma do processo de desenvolvimento de produtos

Quando desenvolve a peça piloto (protótipo), os responsáveis pelo desenvolvimento do produto buscam sanar todos os possíveis processos custosos para a produção, de modo a diminuir o tempo desta fase. Essas decisões de projeto são baseadas nas experiências tanto da costureira pilotista (aquela cuja função e produzir as peças piloto) quanto nos conhecimentos da empresária. Caso ocorra algum problema posteriormente, as informações são prontamente repassadas aos desenvolvedores e soluções alternativas são buscadas. Logo os problemas na 
cadeia de produção são avaliados quando é confeccionada a peça piloto, sendo corrigidos e as mudanças efetuadas até a validação da versão final da mesma.

Desde a concepção do produto até a sua comercialização (mediante pedidos) são gastos em média 30 dias (Figura 4). A organização não dispõe de um acervo sobre a evolução de seus produtos e serviços, no entanto monitoram-se informações de vendas e nível de satisfação dos clientes pelos relatos da equipe de vendas, devido ao contato direto com o cliente, ou pelo feedback dados pelas empresas private label.

\section{ANÁLISE E DISCUSSÃO}

Embora os modelos de processo de desenvolvimento de produto possam variar dependendo da empresa e do item, as etapas usualmente são similares. Portanto, o importante é entender como as etapas são gerenciadas. Com esse objetivo, os dados coletados no estudo de caso foram analisados e interpretados considerando o embasamento teórico do presente trabalho, ou seja, através da conexão entre a teoria e a prática. Devido ao incentivo de agentes de fomento como SENAI e SINVESD para a adoção do modelo fast fashion pelas empresas da região, recentemente a empresa promoveu algumas mudanças para a inserção nesse modelo passando a ser classificada como produtora de moda rápida, sendo que muitas das práticas sugeridas nesse novo modelo adotado já eram observadas, como atuar em um mercado altamente diversificado e de produzir em pequenos lotes (semi-exclusivos) que permitem renovar permanentemente seus modelos dentro de uma mesma estação, uma vez que não produzem coleções. Além disso, há ainda o fato da busca de informações sobre as necessidades dos consumidores diretamente no ponto de vendas, no caso através dos vendedores e conversas informais com demais clientes varejistas, fazendo com que esses desejos sejam traduzidos em seus produtos. 


\section{Fluxograma do processo produtivo da empresa}

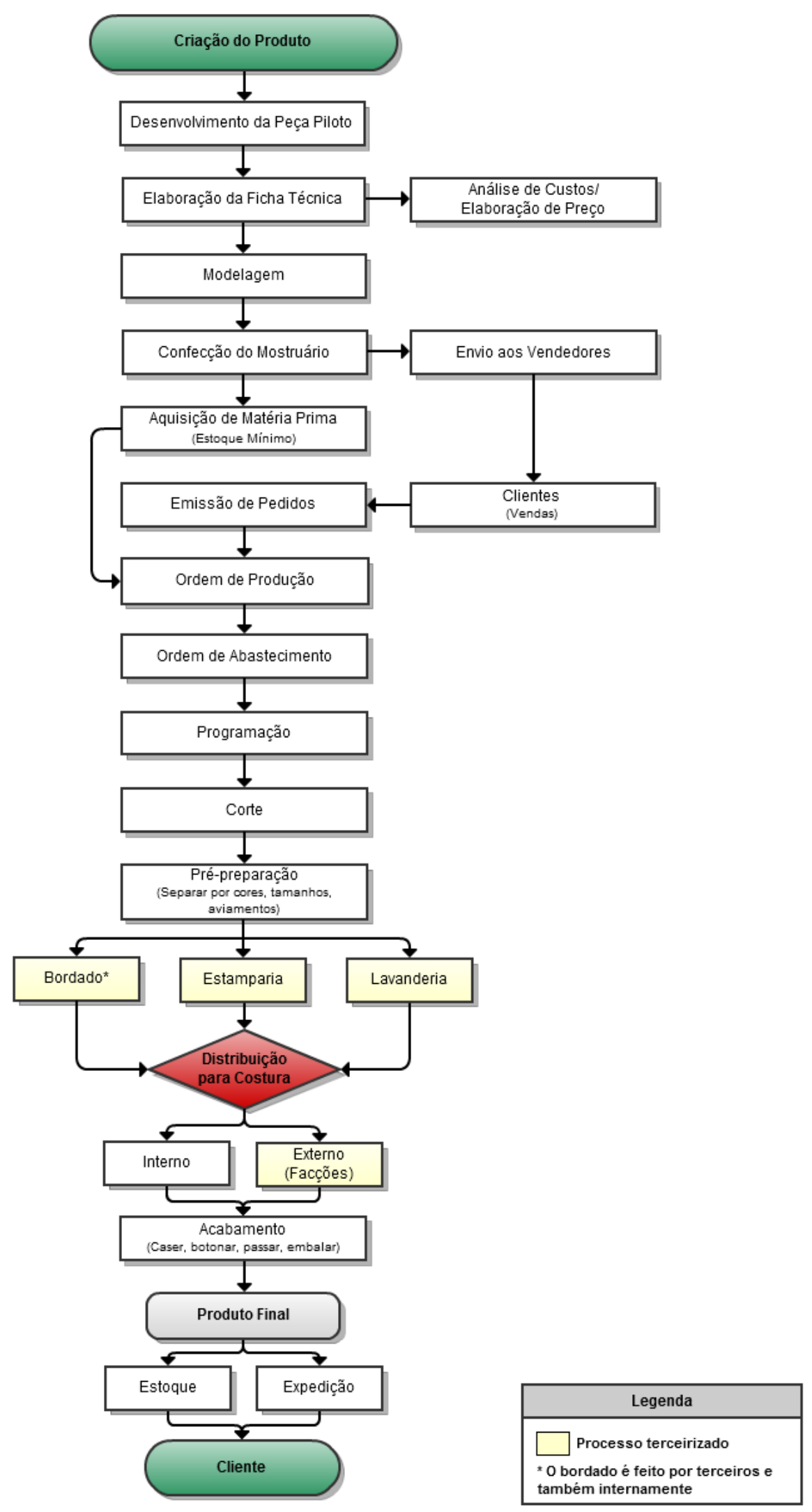


FIGURA 4 - Fluxograma da cadeia produtiva

Apesar de atividades compartilhadas com as do modelo fast fashion, alguns procedimentos exigiram transformações sob o que era até então praticado. A principal mudança foi na produção. Em busca de diminuir o tempo do processo de confecção da camisa adotou-se o sistema de produção em células. Dessa forma, além da redução do lead time e consequentemente ganho em produtividade, esse novo arranjo conferiu ao processo a diminuição de estoques intermediários e redução de seus custos, além de melhora no controle de qualidade. Sob esse último aspecto observa-se maior preocupação da empresa com controle de qualidade. São confeccionados internamente aqueles produtos mais elaborados e terceirizado o restante da produção, contrariando as críticas feitas aos produtos de moda rápida. Outra mudança inerente à adoção desse sistema de produção foi em relação à mensuração do tempo de cada etapa da produção, que passa a ser cronometrado durante a confecção da peça piloto e não mais uma média dessas operações durante a produção propriamente dita, isso porque na moda rápida um produto pode não ser produzido em mais de um lote. $\mathrm{O}$ fato de produzir novos modelos semanalmente elucida essa situação (flexibilidade).

Entretanto é no processo criativo que ainda se percebe traços remanescentes do modelo anteriormente empregado pela empresa, a moda pronta. Os produtos da empresa ainda são em sua maioria baseados em best-sellers ou inspirados em marcas consagradas no mercado. Entretanto, percebeu-se também durante as entrevistas que há uma vertente que se baseia nos feedbacks de vendedores além de inspirações em personagens de novelas. Pode-se concluir que a empresa, apesar de ser classificada como produtora de fast fashion, ainda traz em seus processos e estratégias características da moda pronta, ou seja, ela ainda está em transição entre os dois modelos.

Em relação às características do produto, assim como afirmado por Cietta (2010), apesar das diversidades regionais de seus consumidores citadas pelos empresários, é a comunicação entre a empresa e consumidores mediada por vendedores os quais a capacita a oferecer produtos orientados ao mercado local, além da experiência dos mesmos no ramo, diferentemente de estilistas/designers que já atuaram na empresa. Apesar de parte da fabricação ser para outras marcas, a indústria é capaz de atender mercados que vão desde a classe $\mathrm{C}$ até a classe $\mathrm{A}$. Estas parecem ser características das pequenas e médias indústrias de confecção de moda rápida brasileira, que procuram a competitividade mediante a criatividade, embora façam isso de forma 
pouco profissionalizada, sem a orientação de estilistas. A adoção de um método mais estruturado pode robustecer o sistema de desenvolvimento de produtos da empresa e consequentemente aumentar a chance de sucesso de seus produtos, além de atuar no fortalecimento da marca própria, que é essencial às empresas da moda. Não se pode criar uma marca sólida no mercado atuando como terceirizada de outras empresas, no modelo private label.

\section{CONSIDERAÇÕES FINAIS}

A indústria têxtil é um importante segmento produtivo para o Brasil. Entretanto é um setor pouco estudado e que necessita de procedimentos e ferramentas que melhorem sua eficiência, perante a concorrência das importações. O lançamento de produtos diferenciados rapidamente tem sido apontado como saída para a crescente pressão competitiva. Fato que torna a indústria da moda muito complexa devido à rápida obsolescência de seus produtos e que consequentemente estabelece um desafio em projetá-los.

A mudança mais significativa que está ocorrendo na cadeia produtiva da moda é o fato da produção passar a ser ditada pelos clientes finais, que procuram determinar critérios de produto e produção. Esta nova formatação da cadeia está relacionada com a progressiva incorporação do imaterial. A modernização da indústria por meios materiais (investimentos em máquinas e matérias-primas) continua a ser importante, porém cada vez mais não é suficiente (RECH, 2002). A introdução do modelo fast fashion no mercado brasileiro tem acarretado mudanças estruturais nas indústrias de moda para que elas se adaptem a esse novo formato, conforme demonstrado neste artigo. O que se percebe desse estudo é que, diferentemente do que os críticos alegam sobre grandes propulsoras desse modelo, as empresas nacionais de menor porte estão adaptando a moda rápida de forma capaz de ter mudança veloz de seus produtos garantindo a qualidade do produto e as condições adequadas de trabalho (CIETTA, 2010). Esse modelo tem aberto novas possibilidades para que as empresas apostem na flexibilidade e na rapidez de respostas como grande vantagem competitiva.

O fast fashion tem se tornado um modelo de diferenciação principalmente para as pequenas e médias empresas nacionais, com isso a aplicação de um método de desenvolvimento de produto específico para essas instituições tende a orientar e direcionar melhor o desempenho destas empresas. Conforme Kotler (2011) estruturar o processo de desenvolvimento de produto 
acarreta investimento em tecnologia e organização de processos, reduzindo tempo, custos e etapas. A perspectiva para as empresas do fast fashion é de crescimento, portanto precisam se manter em constante processo de mudança e adaptação para favorecer suas estratégias. Contudo, a falta de análises de cases acaba por ser um entrave para as empresas brasileiras que não sabem como esse modelo está obtendo sucesso no país, qual o modelo adotado pelas empresas nacionais e como elas se organizam, além de desconhecerem as vantagens competitivas já produzidas.

\section{REFERÊNCIAS}

CIETTA, Enrico. A Revolução do Fast Fashion: Estratégias e modelos organizativos para competir nas indústrias híbridas. 2 ed. São Paulo: Estação das Letras e Cores, 2010. 267 p.

DELGADO, Daniela. Fast fashion: estratégia para conquista do mercado globalizado. Modapalavra eperiodico, Florianópolis, Ano 1, n.2, p. 2-10, ago./dez. 2008. Disponível em <http://www.ceart.udesc.br/modapalavra/edicao2/files/fast_fashion-daniela_delgado.pdf $>$. Acesso em: 20 maio 2012.

GIL, Antônio Carlos. Métodos e Técnicas de Pesquisa Social. 7 ed. São Paulo: Atlas, 2019.

KOTLER, Philip. Administração de Marketing: análise, planejamento, implementação e controle. 5 ed. São Paulo: Editora Atlas, 2011. 726p.

MONTEMEZZO, Maria Celeste de Fátima. Diretrizes metodologias para o projeto de produtos de moda no âmbito acadêmico. 97f. Dissertação (Mestrado em Desenho Industrial) - Faculdade de Arquitetura,

Universidade Estadual Paulista, Bauru, 2003.

OLIVEIRA, Geraldo. Construindo um sistema de desenvolvimento de produtos em empresa têxtil por intermédio de gestão de portfólio e de QFD. 2007. 188f. Dissertação (Mestrado em Engenhara de Produção) Departamento de Engenharia de Produção, Universidade Federal de Minas Gerais, Belo Horizonte, 2007.

PALOMINO, Erika. A moda. 1 ed. São Paulo: Publifolha, 2002. 104 p.

RECH, Sandra; PERITO, Renata. Sobre tendências de moda e sua difusão. Revista DAPesquisa, Florianópolis, v. 3, n. 2, p. 1-7, ago. 2008/jul. 2009. Disponível em

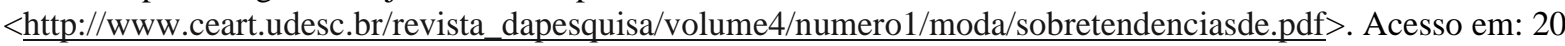
maio 2018.

RECH, Sandra. Moda: por um fio de qualidade. 1 ed. Florianópolis: UDESC, 2002.

SLACK, Nigel et al. Administração da Produção. 8 ed. São Paulo: Atlas, 2018.

SANTIAGO, Cláudia; MORELLI, Graziela. Inovação no Varejo: fast fashion e pop-up stores. In: Congresso de Inovação, Tecnologia e Sustentabilidade, 1, 2010, Brusque. 11 p. Disponível em:

$<$ http://sites.unifebe.edu.br/congressoits2010/artigos/artigos/062_-

_INOVACAO_NO_VAREJO_FAST_FASHION_E_POP_UP_STORES.pdf >. Acesso em: 13 out. 2017. 